\title{
Acute Cytomegalovirus (CMV) Infection Associated with Hemophagocytic Lymphohistiocytosis (HLH) in an Immunocompetent Host Meeting All Eight HLH 2004 Diagnostic Criteria
}

\author{
Alex K. Bonnecaze ${ }^{1}$, Wesley G. Willeford ${ }^{1}$, Peter Lichstein ${ }^{1}$, Jill Ohar $^{2}$ \\ 1. Department of Internal Medicine, Wake Forest University Baptist Medical Center 2. Department of \\ Pulmonary, Critical Care, Allergy and Immunologic Diseases, Wake Forest University Baptist Medical \\ Center
}

$\square$ Corresponding author: Alex K. Bonnecaze, abonneca@wakehealth.edu Disclosures can be found in Additional Information at the end of the article

\section{Abstract}

Hemophagocytic lymphohistiocytosis (HLH) is a rare and often deadly syndrome characterized by severe inflammation and cytokine dysregulation. The disease is defined by the HLH-2004 criteria, requiring five of eight findings, and is further differentiated into either primary or secondary causes. Primary HLH tends to be of genetic etiology, while secondary HLH results from other insults such as infection. Secondary HLH is most commonly associated with viral infections in immunocompromised patients. Acute cytomegalovirus (CMV) associated HLH in the immunocompetent host is exceedingly rare and only documented in four case reports to date. We describe the fifth documented case of CMV-associated HLH in an immunocompetent patient, and furthermore, we demonstrate that this patient is the first published case of its type to satisfy all eight of HLH-2004 criteria.

Received 12/19/2016 Review began 12/21/2016 Review ended 02/22/2017 Published 03/02/2017

\section{C) Copyright 2017}

Bonnecaze et al. This is an open access article distributed under the terms of the Creative Commons Attribution License CC-BY 3.0., which permits unrestricted use, distribution, and reproduction in any medium, provided the original author and source are credited.
Categories: Infectious Disease, Internal Medicine, Other

Keywords: hemophagocytic lymphohistiocytosis, hlh, cytomegalovirus, cmv, immunocompetent, hlh2004

\section{Introduction}

Hemophagocytic lymphohistiocytosis (HLH) is a devastating and rare disorder with an incidence of only 1.2 cases per million patients per year, with a startlingly high mortality rate of $47 \%$ [1]. This disease entity is characterized by defective natural killer cell cytotoxicity, which results in an inappropriately robust activation of macrophages and leads to engulfment of other blood cells. The resulting syndrome is one of high fever, hepatosplenomegaly, lymphadenopathy, and cytopenias. Tseng, et al. found that $60 \%$ of 96 patients who met the 2004 HLH diagnostic criteria had leukopenia, 20\% had hepatosplenomegaly, and 20\% developed jaundice [2]. Due to severe fevers, HLH is frequently mistaken for a septic syndrome, leading to profound delays in time to diagnosis of this rare condition. Tseng, et al. also found that the median time to diagnosis of HLH was 34.5 days [2]. Other clinical presentations reported in the literature include fever of unknown origin, hepatitis and acute liver failure, and neurological abnormalities [3].

HLH is traditionally divided into primary and secondary causes. Cases of primary HLH result 
from genetic abnormalities that lead to defective protein function in the cytolytic secretory pathway, and $80 \%$ of these cases present in the first year of life [3]. Examples of genetic conditions associated with primary HLH include Griscelli syndrome 2 (GS2) and ChediakHigashi disease (CHD). Secondary HLH is typically caused by an exogenous insult in an immunocompromised patient. Common causes are Epstein-Barr virus (EBV), cytomegalovirus (CMV), human immunodeficiency virus (HIV), hepatitis A virus, Herpesviridae, and bacterial, parasitic, and fungal etiologies [3]. CMV-associated HLH has been reported in a variety of immunocompromised states including solid organ transplantation, infection, and autoimmune disease [1]. CMV-associated HLH in an immunocompetent patient has only been reported in the literature on four other occasions [1-2, 4-5]. HLH is defined by meeting at least five of eight HLH 2004 diagnostic criteria [6]. These criteria include: the presence of fever, splenomegaly, cytopenias affecting greater than or equal to two of three lineages in the peripheral blood, hypertriglyceridemia ( $\geqslant 265 \mathrm{mg} / \mathrm{dL}$ ), hemophagocytosis in the bone marrow, spleen, or lymph nodes, soluble CD25 > $2400 \mathrm{U} / \mathrm{mL}$, low or absent natural killer cell (NK-cell) activity, and ferritin $\geqslant 500 \mu \mathrm{g} / \mathrm{L}$. Since the introduction of these guidelines, mortality due to HLH has dropped by $30-35 \%$, and this is likely due to early recognition [1].

\section{Case Presentation}

A 39-year-old morbidly obese female with poorly-controlled type II diabetes mellitus, hypertension, and obstructive sleep apnea presented with a four-day history of night sweats, fevers, and progressive abdominal pain without nausea, vomiting, or diarrhea. Initial physical examination revealed a temperature of $38.9^{\circ} \mathrm{C}$, heart rate of 113 beats per minute, acanthosis nigricans of the posterior neck, and diffuse epigastric tenderness. Initial laboratory values included a creatinine of $0.86 \mathrm{mg} / \mathrm{dL}$, lactic acid of $2.4 \mathrm{mMol} / \mathrm{L}$, lipase of $48 \mathrm{u} / \mathrm{L}, \mathrm{LDH}$ of $664 \mathrm{u} / \mathrm{L}$, ferritin of $1454 \mathrm{ng} / \mathrm{mL}$, and normal transaminases. A computed tomography (CT) scan of the abdomen and pelvis with contrast was obtained and revealed an acute wedge-shaped splenic infarction, hepatosplenomegaly, abdominal lymphadenopathy, and groundglass opacities in the right lower lung lobe concerning for pneumonia (Figure 1). Additional tests shortly after admission included a negative HIV antibody test, a negative antinuclear antibody screen, and hepatitis screen revealing positive hepatitis-B core antibody (Table 1).

Intravenous moxifloxacin was given to treat a presumptive pneumonia, and antibiotics were later escalated to piperacillin-tazobactam after failure to improve. Vancomycin was added several days later out of concern for possible infectious endocarditis on transthoracic echocardiogram (TTE). The patient denied intravenous drug usage; however, she did acknowledge a history of recurrent dental infections. Subsequent transesophageal echocardiogram (TEE) was delayed, but ultimately, it did not demonstrate any valvular lesions.

On the fifth day of admission, the patient suffered acute hypoxemic respiratory failure believed to be secondary to pneumonia and developing acute respiratory distress syndrome. She was transferred to the medical intensive care unit for more aggressive care and diuresis. Despite these interventions, the patient developed worsening respiratory failure and shock refractory to crystalloid fluid administration. She required intubation and inotropic support. The patient continued to be febrile without improvement of respiratory failure despite negative blood cultures and greater than 10 days of broad-spectrum antibiotics. Piperacillin-tazobactam was changed to meropenem, given worsening clinical picture and concern for multi-drug-resistant organisms, given fever of unknown origin and her history of dental infections.

Factors that suggested HLH at this point included an acute elevation of ferritin, persistent fever, splenomegaly, and new-onset hypertriglyceridema ( $617 \mathrm{mg} / \mathrm{dL})$. By the 20th day of hospitalization, multiple viral studies had been obtained, all of which were unremarkable other than a positive CMV immunoglobulin M (IgM) and CMV immunoglobulin G (IgG). A thorough workup (Table 1) was not suggestive of other etiologies. Given the finding of a positive CMV 
IgM, a CMV-DNA polymerase chain reaction (PCR) was obtained which showed a viral load of $119,611 \mathrm{c} / \mathrm{mL}$. A bronchial alveolar lavage (BAL) was performed due to persistent respiratory failure and pneumonia, and this yielded a positive CMV PCR. A diagnosis of acute CMV infection with highly probable CMV-pneumonia was made. While histopathologic diagnosis of CMV-pneumonia requires visualization of viral inclusion bodies in lung or transbronchial tissue, it is generally accepted that a clinical diagnosis may be made when viral pneumonia is suspected in addition to a positive BAL CMV PCR [7].

Given persistent fevers despite therapy and a markedly elevated ferritin, which continued to increase $(10,000 \mathrm{ng} / \mathrm{mL})$, hematology-oncology was consulted. A bone marrow biopsy was performed and revealed scattered hemophagocytosis (Figure 2). A natural killer (NK) cell function assay revealed absent activity. Soluble CD25 receptor was elevated at $3611 \mathrm{U} / \mathrm{mL}$. At this time, the patient met all eight HLH diagnostic criteria. Additionally, she had demonstrated acute CMV infection via robust viremia and positive CMV PCR on BAL.

Intravenous (IV) ganciclovir therapy was initiated and dosed for renal impairment once CMV viral load was found to be markedly elevated in addition to a positive BAL CMV PCR. Clinically, the patient failed to improve with IV ganciclovir; however, the CMV viral load significantly decreased shortly after antiviral therapy was started (119,611 IU/ml prior to therapy, $2402 \mathrm{IU} / \mathrm{ml}$ five days after therapy, and < $137 \mathrm{IU} / \mathrm{ml} 11$ days after therapy).

Upon diagnosis of HLH, the patient was started on IV dexamethasone therapy (four week taper) without concomitant cytotoxic therapy. While chemotherapy, such as etoposide, is often used to treat HLH, the consulted hematology team felt the patient was a poor candidate for this. Clinical improvement was noted within several days of initiating IV dexamethasone. The patient eventually recovered after suffering several complications during therapy, including an episode of Proteus mirabilis septicemia secondary to central venous catheter line infection, multiple intubations, and acute renal failure secondary to acute tubular necrosis, which required renal replacement therapy. She was discharged on hospital day 58.

Her outpatient course was complicated by poor therapeutic adherence, post-traumatic stress disorder, and hypoventilation secondary to obesity and obstructive airway disease. She went on to require placement of a tracheostomy due to hypoventilation. She continues to follow-up with oncology and her primary care provider. Informed consent was obtained from the patient for this study. 


\section{Cureus}

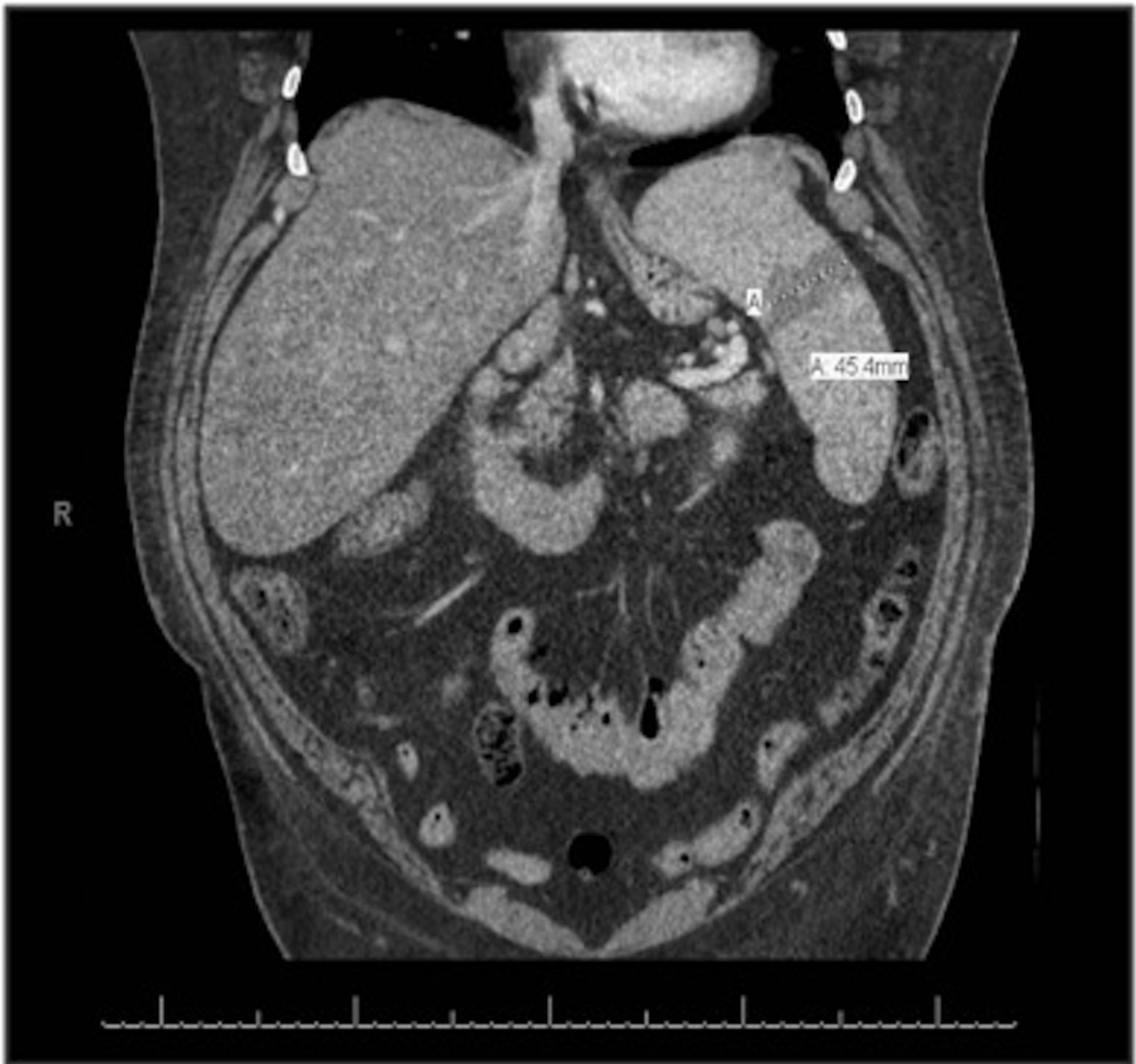

FIGURE 1: Acute splenic infarction on admission - CT-abdomen imaging. Hepatosplenomegaly and abdominal lymphadenopathy were also noted.

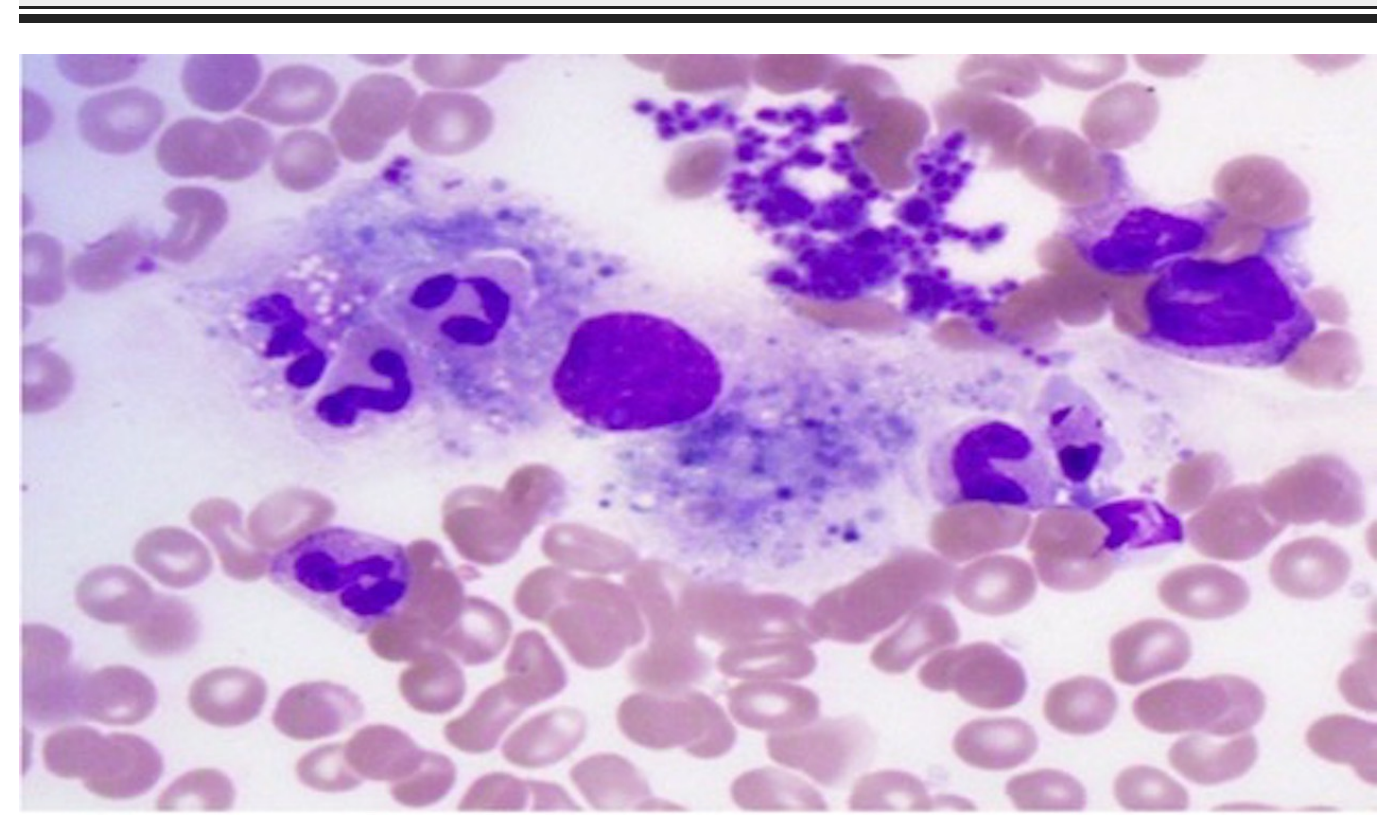

FIGURE 2: Hemophagocytosis on bone marrow biopsy. 


\begin{tabular}{|c|c|c|c|}
\hline$\underline{\text { Lab }}$ & $\underline{\text { Value }}$ & $\underline{\text { Lab }}$ & Value \\
\hline Respiratory Virus Panel (RVP) & Negative & SSA/SSB Antibodies & Negative \\
\hline Hepatitis Panel & $\begin{array}{l}\text { Negative other than } \\
\text { HBV Core Ab }\end{array}$ & $\begin{array}{l}\text { Transesophageal } \\
\text { Echocardiogram }\end{array}$ & No valvulopathy \\
\hline HIV & Negative & Antiphospholipid Antibody & Negative \\
\hline Rheumatoid Factor (RF) & Negative & $\begin{array}{l}\text { Rocky Mountain Spotted } \\
\text { Fever \& Lyme Serology }\end{array}$ & Negative \\
\hline ANCA & Negative & Ferritin & $10,253 \mathrm{ng} / \mathrm{mL}$ \\
\hline CMV IgM & Positive & Triglycerides & 402 mg/dL \\
\hline CMV IgG & Positive & $T \max$ & $103.9^{\circ} \mathrm{F}$ \\
\hline CMV PCR & $119,611 \mathrm{c} / \mathrm{mL}$ & СВС & $\begin{array}{l}\text { Hemoglobin } 8.5 \mathrm{~g} / \mathrm{dL} \\
\text { Platelets } 78,000\end{array}$ \\
\hline $\begin{array}{l}\text { Bronchial Alveolar Lavage (BAL) } \\
\text { CMV PCR }\end{array}$ & Positive & BAL HSV PCR & Negative \\
\hline $\begin{array}{l}\text { BAL } \\
\text { Aspergillus/Pneumocyst/Legionella }\end{array}$ & Negative & Bone Marrow Biopsy & Hemophagocytosis \\
\hline Natural Killer Cell (NK) Activity & Absent & Splenomegaly & Present \\
\hline Acid Fast/Fungal Blood Cultures & Negative & Soluble CD25 & $3611 \mathrm{U} / \mathrm{mL}$ \\
\hline
\end{tabular}

\section{TABLE 1: Summary of inpatient laboratory and imaging findings.}

Hepatitis B virus - HBV, Anti-neutrophil cytoplasmic antibodies - ANCA, Complete blood count - CBC.

\section{Discussion}

Hemophagocytic lymphohistiocytosis, defined by the HLH-2004 criteria, represents a syndrome of cytokine dysregulation and severe inflammatory response. Additionally, it is one of only several diseases featuring a markedly elevated ferritin level in addition to adult onset Still's disease and lymphoma. While HLH primarily affects immunocompromised patients, it is also possible for immunocompetent individuals to be affected. Even more rare is CMV-associated HLH in the immunocompetent patient, which has been documented only four times in the literature. Tsuda, Hot, and Tseng all report cases featuring positive CMV serology and bone marrow biopsy revealing hemophagocytosis; however, they did not report measuring NK-cell activity or CD 25 levels [2, 4-5]. Atim-Oluk, et al. argue their case is the first of its kind to diagnose HLH without bone marrow biopsy; however, they also did not measure NK-cell activity and CD 25 levels [1]. This case also had potential overlap with syndromes such as adult 
onset Still's disease given the lack of aforementioned studies and a bone marrow biopsy. None of these cases reported finding CMV in multiple body fluids, compared to our patient who demonstrated CMV in both blood and alveolar lavage fluid.

The patient presented above met all eight of the HLH 2004 diagnostic criteria with an elevated ferritin to $10,253 \mathrm{ng} / \mathrm{mL}$, triglycerides of $402 \mathrm{mg} / \mathrm{dL}$, anemia and thrombocytopenia, high fevers, absence of natural killer cell activity, soluble CD25 of $3611 \mathrm{U} / \mathrm{mL}$, confirmed splenomegaly by computed tomography scan (Figure 1), and evidence of hemophagocytosis seen on bone marrow biopsy (Figure 2). Furthermore, CMV as the etiology for our case is better supported than the previously mentioned cases (Table 2). Tsuda, et al. had only positive values for CMV IgG and IgM; Hot, et al. had positive CMV IgM and CMV PCR revealing 41,000 viral copies/mL; Tseng, et al. did not specify in their paper; and Atim-Oltuk, et al. had positive values for CMV IgG, IgM, and a CMV PCR with 19,000 viral copies/mL. Our patient demonstrated positive values for CMV IgG, IgM, CMV PCR (119,611 copies/mL), and a bronchial alveolar lavage with qualitative CMV PCR positivity.

Despite severe CMV infections traditionally affecting neonatal and immunocompromised patients, disease in immunocompetent patients is likely underestimated. While worldwide CMV seropositivity ranges from $40-100 \%$, the vast majority of healthy adults exposed to the virus experience an asymptomatic course or mild mononucleosis-like symptoms [7]. Acute CMV viremia in immunocompetent individuals has been documented to cause colitis, meningitis, encephalitis, myelitis, and bone marrow suppression [8]. One possible theory as to why these individuals are affected is that common conditions, such as poorly controlled diabetes mellitus and kidney disease, may create some degree of immune dysfunction. While immunocompromised individuals are traditionally thought as those suffering specific genetic disorders, taking immune-suppressive drug therapy, or suffering systemic infections such as HIV, many chronic conditions likely create a degree of immunosuppression that is not accounted for. Our patient suffered from poorly controlled diabetes mellitus in addition to morbid obesity, thus potentially creating some degree of functional immune deficiency. This theory would also explain why nearly 400 reports of seemingly healthy individuals suffering severe CMV complications exist [9]. While relative immunodeficiency is difficult to assess, it should be noted our patient did have a normal level of IgA, IgM, and IgG. Future research examining correlations between specific comorbidities and severity of CMV infection in immunocompetent patients would provide further insight to this issue. While it is highly probable that our patients' HLH was induced from her acute multi-organ CMV infection, neither our case nor the prior documented cases can definitively prove this.

One of the more interesting findings in our case was the presence of splenic infarctions. Justo, et al. performed a meta-analysis that revealed that thrombosis in the setting of uncontrolled CMV infection has been mentioned in the literature almost 100 times [10]. The article goes on to state that deep venous thrombosis, pulmonary embolism, and splanchnic vein thrombosis are the most common thromboses associated with acute CMV infection, but splanchnic venous thrombosis is more common in immunocompetent patients.

With regard to our patient's therapeutic regimen, she was given intravenous gangciclovir when high levels of viremia were discovered. While there is no evidence for IV gangiclovir in acute primary CMV infection, benefit does exist in cases of CMV pneumonia, which our patient likely had, given the BAL findings [7]. Once the final diagnosis for HLH was determined, she was given high dose dexamethasone (without etoposide). Per guidelines from the Histiocyte Society (HLH-94), therapy traditionally involves "remission treatment" consisting of eight weeks etoposide and dexamethasone. Further therapy varies based on subtype of HLH and whether or not remission occurs [1]. 


\section{Cureus}

\begin{tabular}{|c|c|c|c|}
\hline Author & Age/Sex & Diagnosis of CMV & Diagnostic Criteria for HLH \\
\hline $\begin{array}{l}\text { Tsuda, Shirono, et al., } \\
1996 \text { [5] }\end{array}$ & $21 \mathrm{M}$ & (+) CMV IgG and IgM & $\begin{array}{l}\text { Fever, Splenomegaly, Cytopenia, Ferritin 1314, } \\
\text { Positive BMB }\end{array}$ \\
\hline Hot, et al., 2008 [4] & $32 \mathrm{~F}$ & $\begin{array}{l}\text { (+) CMV IgM, CMV PCR } \\
41,000\end{array}$ & $\begin{array}{l}\text { Fever, Splenomegaly, Cytopenia, Ferritin 88,300 } \\
\text { ng/mL, Positive BMB }\end{array}$ \\
\hline $\begin{array}{l}\text { Yu-Izu Tseng, et al., } \\
2011[2]\end{array}$ & N/A & Generic Criteria & $\begin{array}{l}\text { Reportedly met HLH2004 criteria and BMB+ (No } \\
\text { further details) }\end{array}$ \\
\hline $\begin{array}{l}\text { Atım-Oltuk, et al., } \\
2013 \text { [1] }\end{array}$ & $48 \mathrm{~F}$ & $\begin{array}{l}\text { CMV IgG/lgM (+), CMV } \\
\text { PCR 19,000 }\end{array}$ & $\begin{array}{l}\text { Fever, Splenomegaly, Ferritin 40,000 ng/mL, } \\
\text { Cytopenia, Hypertriglyceridemia }\end{array}$ \\
\hline
\end{tabular}

TABLE 2: Prior cases of CMV-associated HLH infection in immunocompetent hosts.

\section{Conclusions}

CMV-induced HLH in the immunocompromised patient is a rare disease, but in an immunocompetent patient, the diagnosis is rarer still. To date, our case represents only the fifth report of this particular scenario. Furthermore, our case is the only one to meet all eight of the HLH 2004 diagnostic criteria, and it is the only one to demonstrate CMV by PCR and immunologically in the blood and by PCR in an affected organ system. Clinicians should additionally consider other comorbidities, such as poorly controlled diabetes, which may lead to a lesser degree of immunodeficiency in critically ill patients. Other cases may be yet unpublished, but due to the rarity, rapidity, and severity of HLH, this particular syndrome may be underrepresented in the literature.

\section{Additional Information \\ Disclosures}

Human subjects: Consent was obtained by all participants in this study. Conflicts of interest: In compliance with the ICMJE uniform disclosure form, all authors declare the following: Payment/services info: All authors have declared that no financial support was received from any organization for the submitted work. Financial relationships: All authors have declared that they have no financial relationships at present or within the previous three years with any organizations that might have an interest in the submitted work. Other relationships: All authors have declared that there are no other relationships or activities that could appear to have influenced the submitted work.

\section{References}

1. Atim-Oluk M: Cytomegalovirus associated haemophagocytic lymphohistiocytosis in the immunocompetent adult managed according to HLH-2004 diagnostic using clinical and serological means only. Eur J Microbiol Immunol (Bp). 2013, 3:81-89. 10.1556/EuJMI.3.2013.1.12

2. Tseng YT, Sheng WH, Lin BH, et al.: Causes, clinical symptoms, and outcomes of infectious diseases associated with hemophagocytic lymphohistiocytosis in Taiwanese adults. J Microbiol Immunol Infect. 2011, 44:191-197. 10.1016/j.jmii.2011.01.027

3. Usmani GN, Woda BA, Newburger PE: Advances in understanding the pathogenesis of HLH . Br J Haematol. 2013, 161:609-622. 10.1111/bjh.12293 


\section{Cureus}

4. Hot A, Madoux MH, Viard JP, et al.: Successful treatment of cytomegalovirus-associated hemophagocytic syndrome by intravenous immunoglobulins. Am J Hematol. 2008, 83:159162. 10.1002/ajh.21008

5. Tsuda H, Shirono K: Successful treatment of virus-associated haemophagocytic syndrome in adults by cyclosporin A supported by granulocyte colony-stimulating factor. Br J Haematol. 1996, 93:572-575. 10.1046/j.1365-2141.1996.d01-1707.x

6. Henter JI, Horne A, Aricó M, et al.: HLH- 2004: diagnostic and therapeutic guidelines for hemophagocytic lymphohistiocytosis. Pediatr Blood Cancer. 2007, 48:124-131.

10.1002/pbc.21039

7. Grilli E, Galati V, Bordi L, et al.: Cytomegalovirus pneumonia in immunocompetent host: case report and literature review. J Clin Virol. 2012, 55:356-359. 10.1016/j.jcv.2012.08.010

8. Al-Omari A, Aljamaan F, Alhazzani W, et al.: Cytomegalovirus infection in immunocompetent critically ill adults: literature review. Ann Intensive Care. 2016, 6:110. 10.1186/s13613-0160207-8

9. Lancini D, Faddy HM, Flower R, Hogan C: Cytomegalovirus disease in immunocompetent adults. Med J Aust. 2014, 201:578-580. 10.5694/mja14.00183

10. Justo D, Finn T, Atzmony L, et al.: Thrombosis associated with acute cytomegalovirus infection: a meta-analysis. Eur J Intern Med. 2011, 22:195-199. 10.1016/j.ejim.2010.11.006 